\title{
Diaphragm valve head loss coefficients for coarse particles transported in a non-Newtonian carrier fluid
}

\author{
V.G. Fester Cape Peninsula University of Technology, South Africa \\ A.M. Kabwe Cape Peninsula University of Technology, South Africa \\ P.T. Slatter Rheology and Materials Processing Centre, RMIT, Australia
}

\begin{abstract}
The head loss coefficients for coarse particles in water have been tested in turbulent flow in various types of fittings and valves (Turian et al., 1983) and it was found that they are the same as that for water only. This has not been done for coarse particles in a non-Newtonian carrier fluid to date, particularly in laminar flow. Efficient design is only possible if reliable loss coefficient data are available. For paste slurries which are in use in many industrial settings, this situation is exacerbated by the necessity to use less water, resulting in laminar flow designs becoming more common. In many applications, these pastes could contain coarse particles. The use of diaphragm valves is common in the mineral processing industries.
\end{abstract}

The objective of this work is to evaluate the head loss coefficients for coarse particles transported in a nonNewtonian carrier in a diaphragm valve in laminar, transitional and turbulent flow. A silica sand-kaolin slurry was tested at various concentrations in a diaphragm valve.

This work provides important information on the behaviour of coarse particles in a non-Newtonian carrier fluid when flowing through a diaphragm valve.

\section{Introduction}

As the use of co-disposal in the mining industry has become accepted technology, so the methods for predicting the pressure gradients or frictional losses for optimum pump design have developed. The behaviour of these hybrid mixtures consisting of a non-Newtonian carrier and a coarse burden are complex and conventional methods are not able to predict behaviour for many operational conditions (Pullum et al., 2006). Even if the yield stress of the carrier fluid exceeds that required for static support of coarse particles, the suspension will still stratify when sheared (Pullum et al., 2006). For high concentration suspensions, the frictional loss in laminar flow is dominated by the rheology of the fluid. In turbulent flow, the mixture density dominates the frictional loss (Cooke, 2002). The most recent work (Pullum et al., 2010) highlighted the dangers of testing these hybrid mixtures in small diameter pipes for extrapolation to large pipes. The stratified bed flow effect is masked by the viscous nature of the material in small pipes while it is the dominant effect in large pipes. Given the current emphasis on energy reducing technologies, accounting accurately for the losses that arise from pipe fittings, such as valves, becomes a significant and important issue. However, efficient design is only possible if reliable loss coefficient data are available. The accurate estimation of the additional energy losses caused by pipe fittings, such as valves, is important for determining the correct pump size (Massey, 1970). The frictional losses arising from pipe fittings are often referred to as 'minor' losses and are normally neglected when they constitute less than $5 \%$ of the total frictional head losses in the straight pipes (Streeter and Wylie, 1985). However, in shorter pipeline lengths, such as those typically found in the process industry, these minor losses can easily sum up to exceed the losses in the straight pipes (Edwards et al., 1985). The fact that these minor losses can realistically give rise to errors in pump motor sizing up to $50 \%$ was demonstrated by practical example and new loss coefficient data for slurry diaphragm valves in particular (Slatter and Fester, 2010) for commonly accepted 'homogeneous suspensions' of kaolin slurries. This information, as well as stratified bed flow effects on the prediction of frictional losses in straight pipes, necessitated the investigation of the addition of coarse burden to a kaolin slurry on the pressure losses and loss coefficient in a diaphragm valve. 
This whole problem is clouded by at least one serious exacerbating issue. There is a long held view in the literature that "coarse" particles contribute materially to the rheology of the mixture - the yield stress in particular (Duckworth et al., 1986; Coussot and Piau, 1995; Paulsen et al., 2010). By implication, this view supports the contention that the mixture can be treated as a homogeneous fluid. A more recently introduced view (Pullum et al., 2006) states that coarse particles will settle when the mixture is sheared, implying that "coarse" particles cannot contribute materially to the rheology of the mixture, and that heterogeneous striated mechanistic models should be used for flow analysis. The body of literature relevant to this topic contains a direct contradiction with both sides able to produce substantive, convincing experimental data to back up their claims.

Practical results from tests conducted by Charles and Charles (1971) showed that the head loss for $216 \mu \mathrm{m}$ sand particles in shear-thinning clay suspension was six times less than water. Ghosh and Shook (1990) reported, although not quantified, a reduction in head loss for $600 \mu \mathrm{m}$ sand particles in shear-thinning carboxymethyl cellulose (CMC) solutions.

These unresolved issues directly affect this work since the loss coefficient is usually presented as a function of Reynolds number. For the purpose of this paper, these issues are avoided by presenting the loss coefficient $\mathrm{k}_{\mathrm{valve}}$ as a function of the average velocity in the pipe.

\section{Theory and literature review}

\subsection{Definition of loss coefficient}

The loss coefficient is defined as the non-dimensionalised difference in the overall pressure drop between the ends of two long straight pipes when there is a fitting installed, and when there is no fitting (Miller, 1990).

The head loss across a valve can be expressed in terms of the velocity energy head as given in Equation (1) (Edwards et al., 1985):

$$
H_{v}=k_{v} \frac{V^{2}}{2 g}
$$

The loss coefficient of the valve $\mathrm{k}_{\mathrm{v}}$ is given by:

$$
k_{v}=\frac{\Delta p_{v}}{\frac{1}{2} \rho V^{2}}
$$

where $\Delta p_{v}$ is the pressure loss across the fitting and $V$ is the mean flow velocity in the pipe and $\rho$ is the density of the fluid.

The head loss in the valve can therefore be determined from:

$$
H_{v}=\frac{\Delta p_{v}}{\rho g}
$$

In turbulent flow the loss coefficient is independent of the Reynolds number, but in laminar flow a hyperbolic relationship exists between the loss coefficient and the Reynolds number (Edwards et al., 1985):

$$
C_{v}=k_{v} \operatorname{Re}
$$

where $C_{v}$ is a characteristic of a specific valve including its dimensions (Edwards et al., 1985).

The laminar flow loss coefficient constant, $C_{v}$, transition to turbulence and turbulent flow are usually determined from the plots of loss coefficient versus Reynolds number as given by Miller (1990) as shown in Figure 1. 


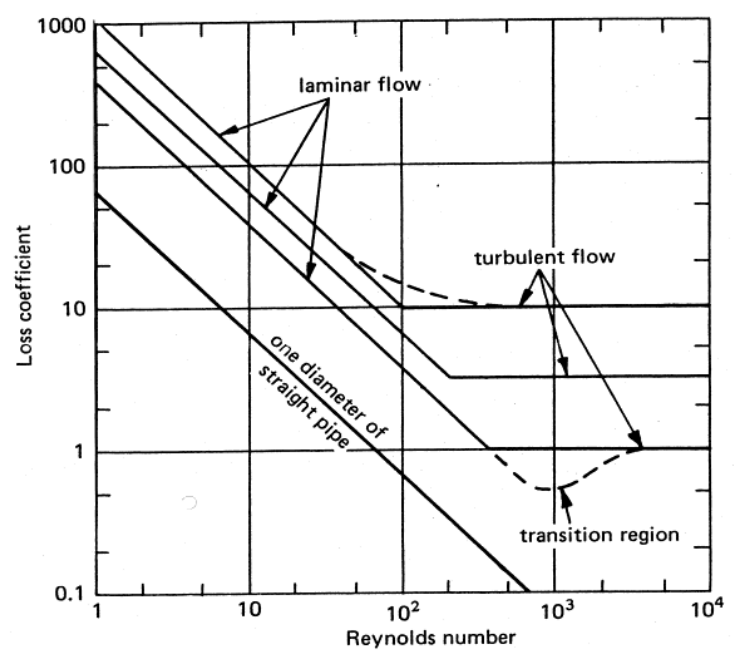

Figure 1 Laminar, transitional and turbulent flow (Miller, 1990)

\subsection{Loss coefficient data for valves}

Miller (1990) classified the loss coefficients of fittings under three classes. Class 1 is definitive loss coefficients that are based on experimental data from two or more sources which have been cross-checked. Class 2 loss coefficients are adequate for design purposes but no agreement has been found between two research programmes. Class 3 loss coefficients are suggested values for situations where experimental data are not available or where the results are from doubtful origin. Loss coefficients for diaphragm valves are classified as Class 3.

The work found in the literature (Hooper, 1981; Miller, 1990; Perry et al., 1997) for diaphragm valves has been obtained using Newtonian fluids only. Kabwe et al. (2010) determined loss coefficient data for various non-Newtonian fluids in diaphragm valves of various sizes. A comparison of the data is given in Table 1. Both Miller (1990) and Perry et al. (1997) provide turbulent loss coefficient data for diaphragm valves in the fully open, $75 \%, 50 \%$ and $25 \%$ open position. Hooper (1981) provides data for fully open valves for both laminar and turbulent flow. The only agreement was the results for the fully open position in turbulent flow between Hooper (1981) and Perry et al. (1997) with $\mathrm{k}_{\text {valve }}$ values of 2.3 and 2.0 respectively and for the $25 \%$ opening between the results of Perry et al. (1997) and Kabwe et al. (2010). Hooper (1981) provided a design correlation for Newtonian fluids flowing through various types of fittings, including diaphragm valves, for both laminar and turbulent flow as given in Equation (5):

$$
k_{\text {valve }}=\frac{C_{\text {valve }}}{\operatorname{Re}}+k\left(1+\frac{1}{D}\right)
$$

where $\mathrm{k}$ is the loss coefficient for fully turbulent flow and D is the diameter of the fitting in inches. In addition to turbulent data, Kabwe et al. (2010) also confirmed that the loss coefficient constant, $C_{\text {valve }}$, obtained by Hooper (1981) is valid for non-Newtonian fluids. A relationship to predict the loss coefficients at different opening positions for laminar and turbulent flow in diaphragms valves was developed by Kabwe et al. (2010) and is given in Equation (6), where $\lambda_{\Omega}$ for a $65 \mathrm{~mm}$ valve was given as 0.57 and $\theta$ is 1 for fully open valves.

$$
k_{\text {valve }}=\frac{1000}{\operatorname{Re}_{3}}+\frac{\lambda_{\Omega}}{\theta^{2.5}}
$$

Data for diaphragm valves is conspicuous by its absence in the Crane Technical Paper (Crane Co., 1999) which is one of the most used design guideline manuals for engineers. Settling slurries were tested in gate and globe valves only by Turian et al. (1983). 
Table 1 Loss coefficient data for diaphragm valves published in literature

\begin{tabular}{|c|c|c|c|c|c|}
\hline \multirow{2}{*}{$\begin{array}{c}\text { Valve } \\
\text { Opening } \\
(\%)\end{array}$} & \multicolumn{4}{|c|}{$\begin{array}{l}\text { Turbulent Flow Loss Coefficient } \\
\qquad\left(k_{\text {valve }}\right)\end{array}$} & \multirow{2}{*}{$\begin{array}{c}\begin{array}{c}\text { Laminar Flow Loss } \\
\text { Coefficient Constan } \\
\left(\boldsymbol{C}_{\text {valve }}\right)\end{array} \\
\text { Hooper }(1981)\end{array}$} \\
\hline & $\begin{array}{l}\text { Miller } \\
(1990)\end{array}$ & $\begin{array}{l}\text { Perry et } \\
\text { al. (1997) }\end{array}$ & $\begin{array}{c}\text { Hooper } \\
(1981)\end{array}$ & $\begin{array}{l}\text { Kabwe et } \\
\text { al. }(2010)^{*}\end{array}$ & \\
\hline 25 & 4 & 21 & & 22 & \\
\hline 50 & 1.2 & 4.3 & & 3.6 & \\
\hline 75 & 0.8 & 2.6 & & 1.77 & \\
\hline 100 & 0.8 & 2.3 & 2.0 & 0.57 & 1,000 \\
\hline
\end{tabular}

The literature shows that no head loss coefficient data has been obtained for coarse particles transported in a non-Newtonian carrier.

\section{Experimental methods}

\subsection{Test rig}

The experiments were conducted on a multipurpose test bench for determining losses across pipe fittings. The tests on the valve were conducted on the $25 \mathrm{~m}$ long $65 \mathrm{~mm}$ internal diameter pipe which contains a test diaphragm valve. Sufficient length is allowed for fully developed flow before and after the test valve. A schematic diagram of the valve test section is shown in Figure 1.

Test fluids were mixed in a $3.4 \mathrm{~m}^{3}$ supply tank. From the supply tank, fluids are pumped out with a centrifugal pump before passing through a heat exchanger. The heat exchanger is followed by two valves coupled in parallel that directed the flow either to the upper part of the rig (which contained the smaller pipes of $25 \mathrm{~mm}, 42 \mathrm{~mm}, 2 \times 46 \mathrm{~mm}, 52.8$ and a $63.08 \mathrm{~mm}$ ID) or the lower part (which contained the contraction from 80 to $40 \mathrm{~mm} \mathrm{ID)}$ ). The upper route is fitted with a KROHNE flow meter of $40 \mathrm{DN}$ before the test specimen and another KROHNE flow meter of $65 \mathrm{DN}$ after the test specimen. After the $40 \mathrm{~mm}$ ID flow meter the fluids could enter any of the test sections. An on/off valve was situated at the beginning and end of each line for isolation, so that only one line is tested at a time. After a fluid had passed a test section it is collected via a common pipe and directed to the supply tank. At the outlet it is possible to send the fluid through a weigh tank used for calibration purposes. A $65 \mathrm{~mm}$ bore diameter diaphragm valves was used in this experimental investigation. The valve was positioned horizontally.

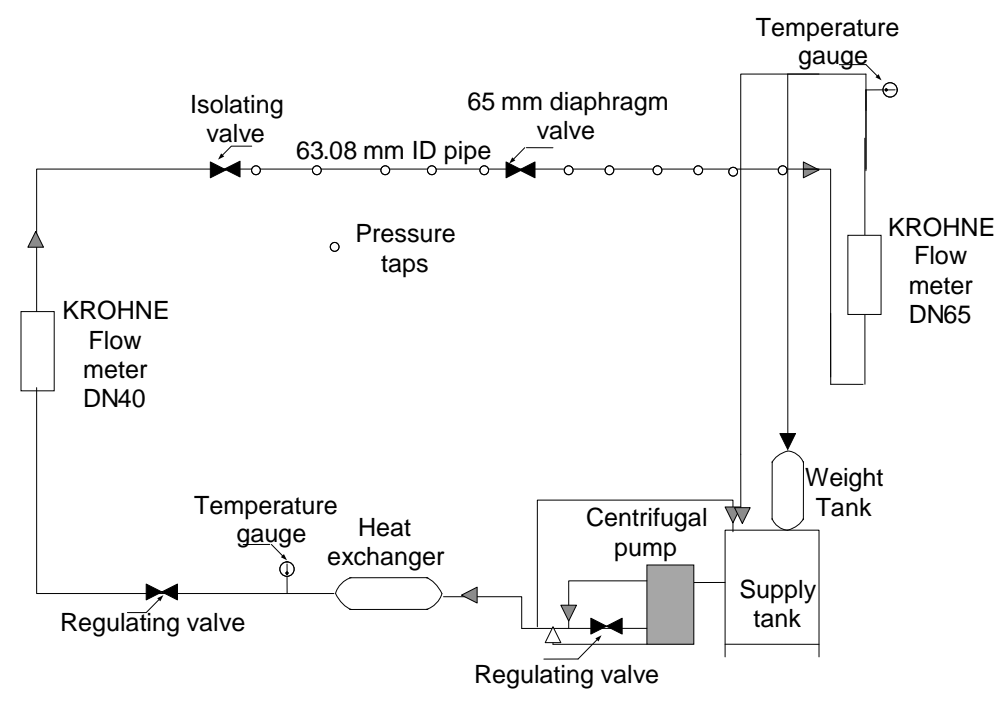

Figure 2 Schematic diagram of the close loop for the $65 \mathrm{~mm}$ ID line 


\subsection{Test procedure}

The fluids were maintained at a temperature between $25^{\circ} \mathrm{C}$ and $30^{\circ} \mathrm{C}$ using a double pipe heat exchanger. The measurement of static pressure at different points upstream (US) and downstream (DS) of the test valve were taken. In total nine points were used, four upstream and five downstream of the test valve. The three points close to the test valve, one point upstream and two points downstream were discarded because they are in the region of influence of the valve.

The pressure drop across the valve $\left(\Delta p_{\text {valve }}\right)$ was determined by extrapolating the fully developed hydraulic grade line to the centre-line of the valve and subtracting the downstream from the upstream pressure drop. The loss coefficient, $k_{v a l v e}$, was then calculated using Equation (2).

\subsection{Test fluids}

Kaolin suspensions at $10 \%$ and $20 \%$ solids concentration were tested. Silica sand with a $\mathrm{d}_{50}$ of $0.7 \mathrm{~mm}$ and $3 \mathrm{~mm}$ was added to the $10 \%$ and $20 \%$ mixtures respectively at concentrations of $2 \%, 5 \%$ and $10 \%$ by volume. The silica sand particle size distributions are given in Figure 3. The particles were sufficiently large not to form part of the carrier fluid and was less that $10 \%$ of the pipe diameter, ensuring a distinct carrier and coarse burden.

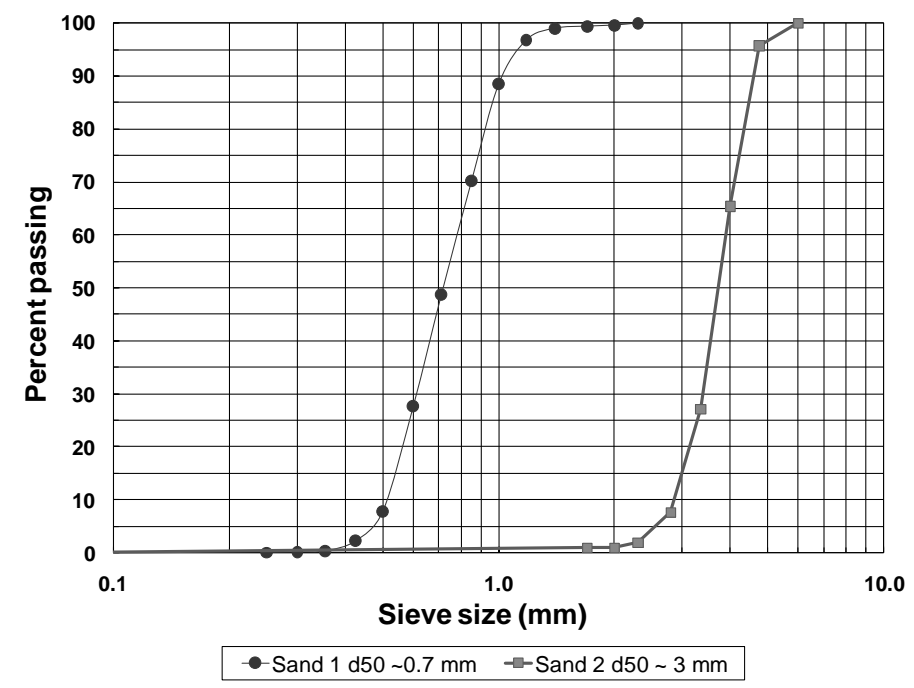

\section{Figure 3 Sieve analysis results of silica sand}

The required mass of silica sand of each concentration was determined using Equation (7).

$$
\text { Mass Sand }=\frac{\varphi \rho_{\text {sand }} V o l_{\text {slurry }}}{1-\varphi}
$$

Where:

$\begin{array}{lll}\varphi & = & \text { sand concentration }(\%) . \\ \text { Vol } & = & \text { volume of the kaolin mixture }\left(\mathrm{m}^{3}\right) . \\ \mathrm{P} & = & \text { sand density }\left(\mathrm{kg} / \mathrm{m}^{3}\right) .\end{array}$


Table 2 Mass of sand at different volumetric concentration

\begin{tabular}{|c|c|c|}
\hline Materials & $\begin{array}{l}\text { Volume of } \\
\text { Slurry }\left(\mathrm{m}^{3}\right)\end{array}$ & $\begin{array}{c}\text { Mass of } \\
\text { Sand (kg) }\end{array}$ \\
\hline Kaolin $10 \%+2 \%$ sand $0.7 \mathrm{~mm}$ & 1 & 54.08 \\
\hline Kaolin $10 \%+5 \%$ sand $0.7 \mathrm{~mm}$ & 0.875 & 122.1 \\
\hline Kaolin $10 \%+10 \%$ sand $0.7 \mathrm{~mm}$ & 0.875 & 257.6 \\
\hline Kaolin $20 \%+2 \%$ sand $3 \mathrm{~mm}$ & 1.5 & 88 \\
\hline Kaolin $20 \%+5 \%$ sand $3 \mathrm{~mm}$ & 1.5 & 220 \\
\hline Kaolin $20 \%+10 \%$ sand $3 \mathrm{~mm}$ & 1.5 & 440 \\
\hline
\end{tabular}

\section{$4 \quad$ Results and discussion}

\subsection{Rheological characterisation of the carrier fluids: kaolin $10 \%$ and $20 \%$}

The rheological parameters were obtained using tube viscometry. This method was selected because the valve test rig consists of five different pipe sizes; and straight pipe test results could be used to produce a plot of shear stress versus pseudo-shear rate using at least three pipe diameters. The Herschel-Bulkley (HB) model was used to determine rheological parameters. The fit of the rheological parameters to the experimental data for the carrier fluids tested are presented in Figure 4 and Table 3. For double the concentration of kaolin, the yield stress increased almost 20 times. The kaolin $10 \%$ was used as carrier fluid for the $0.7 \mathrm{~mm}$ sand and the kaolin $20 \%$ were used as the carrier fluid for $3 \mathrm{~mm}$ sand.

Table 3 Rheological parameters of carrier fluid

\begin{tabular}{lccccc}
\hline Materials & $\begin{array}{c}\mathbf{C}_{\mathbf{v}} \\
\text { Kaolin }\end{array}$ & $\begin{array}{c}\text { Density } \\
\left(\mathbf{k g} / \mathbf{m}^{\mathbf{3}}\right)\end{array}$ & $\begin{array}{c}\boldsymbol{\tau}_{\mathbf{y}} \\
(\mathbf{P a})\end{array}$ & $\mathbf{K}$ & $\mathbf{n}$ \\
\hline Kaolin & $10 \%$ & 1164 & 1 & 1.9 & 0.14 \\
Kaolin & $20 \%$ & 1325 & 40 & 1.31 & 0.44 \\
\hline
\end{tabular}

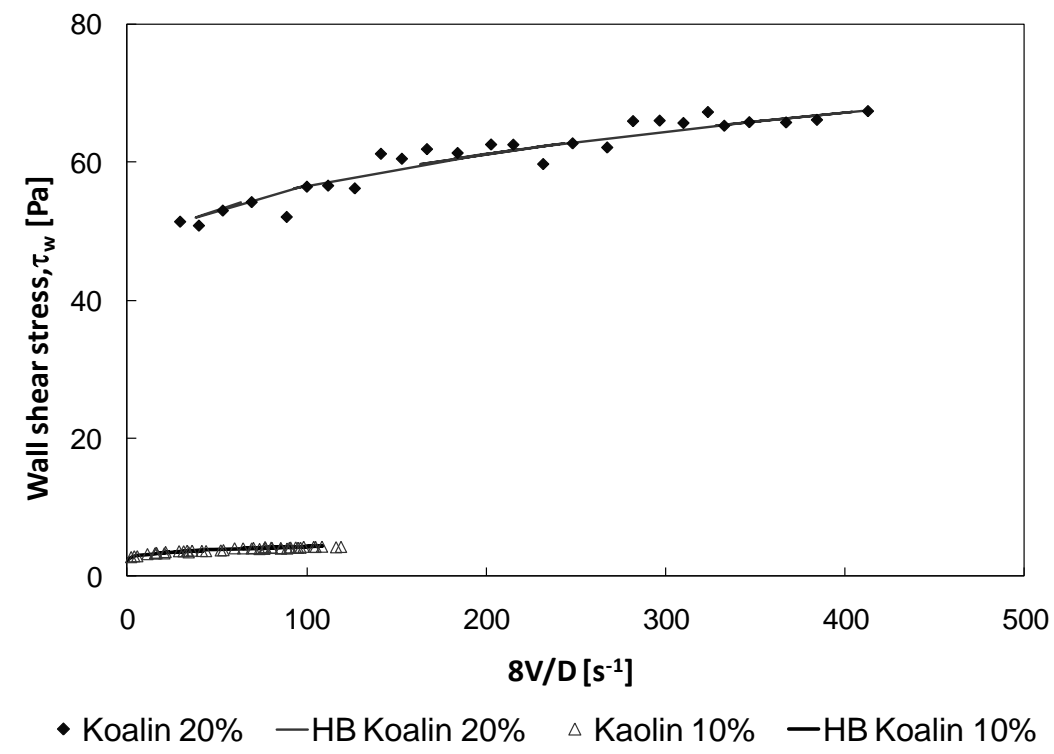

Figure 4 Pseudo-shear diagram for carrier fluids 


\subsection{Head losses in straight pipes for kaolin sand mixtures}

The pressure gradient of the suspensions were determined and plotted as a function of the average velocity of the suspension. Cooke (2002) concluded that coarse particles will be transported as a settled bed in a pipeline if the pressure gradient is more than $2 \mathrm{kPa} / \mathrm{m}$. For the $20 \%$ kaolin suspension with coarse burden, the required pressure gradient for a moving bed of $2 \mathrm{kPa} / \mathrm{m}$ was exceeded.

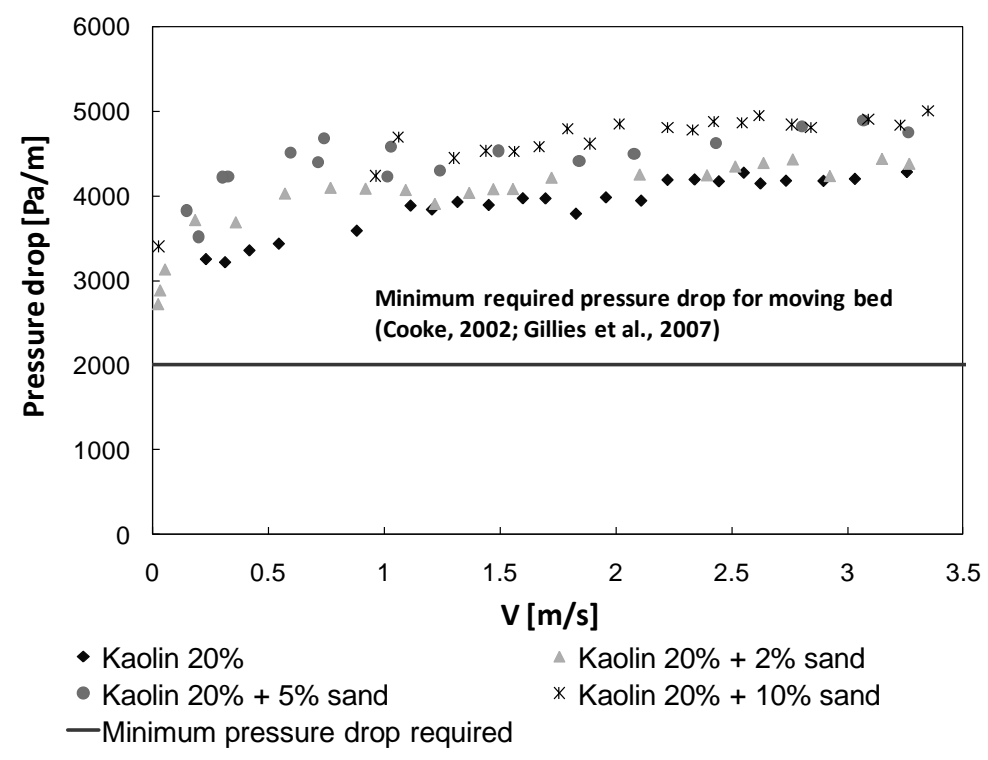

Figure 5 Pressure gradient in $63 \mathrm{~mm}$ straight pipe

\subsection{Head loss coefficient data obtained}

The loss coefficient $\mathrm{k}_{\text {valve }}$ has been determined using Equation (3). The results are presented as a function of the average velocity in the pipe in Figures 6 and 7 for kaolin 10\% and kaolin 20\% sand mixtures. The loss coefficient increase as the velocity decrease below $\mathrm{V} \sim 1 \mathrm{~m} / \mathrm{s}$. At $\mathrm{V}>1$, the loss coefficient is independent of the velocity. This trend is in agreement with the usual $\mathrm{k}_{\text {valve }}$ versus Reynolds number plot.

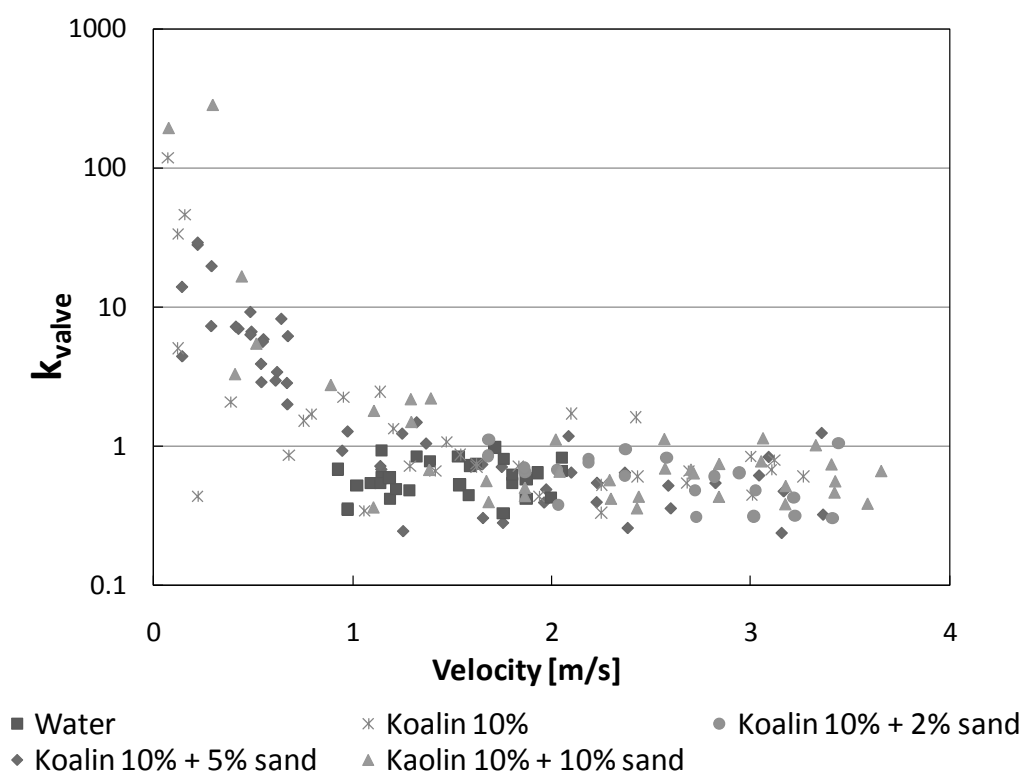

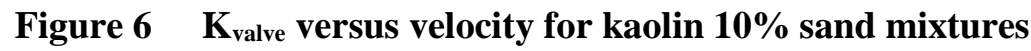




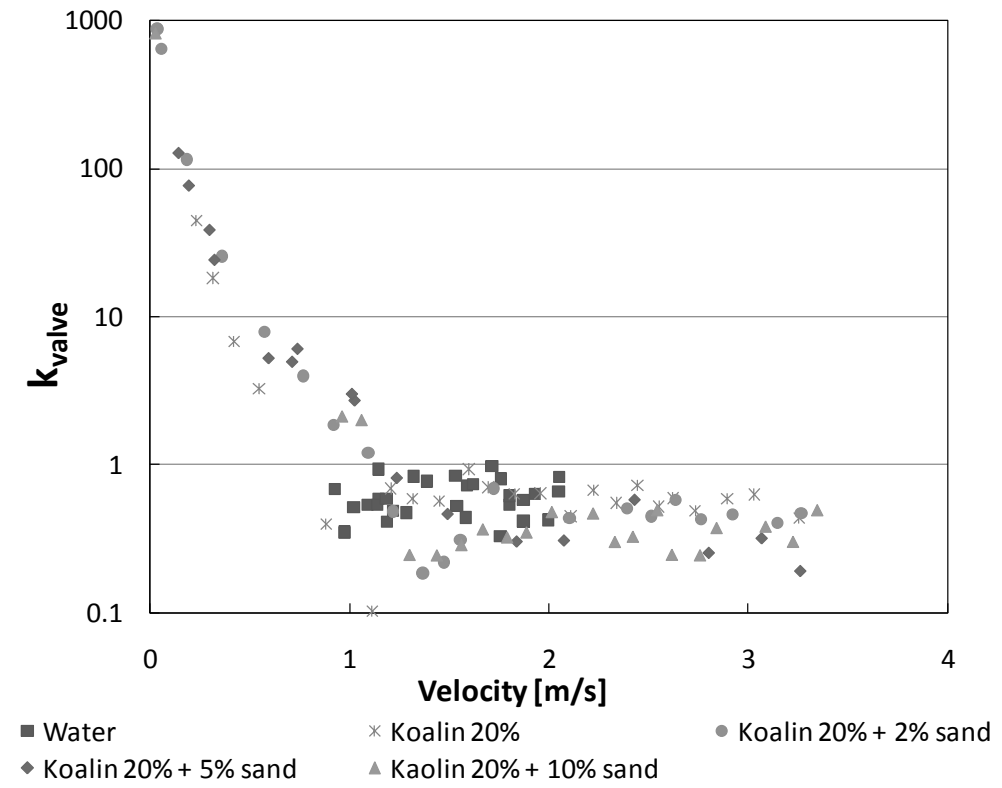

Figure $7 \quad K_{\text {valve }}$ versus velocity for kaolin $20 \%$ sand mixtures

Due to the scatter of results which is typical from these types of tests, it is not clear from Figures 6 and 7 what the role of the particles is. However, when only the turbulent data were analysed, another picture emerged. The average $\mathrm{k}_{\mathrm{valve}}$ result and the standard deviation for each mixture were determined and are presented in Table 4 and Figure 8. These results clearly show a reduction in the head loss coefficient when the coarse particles are introduced.

Table 4 Head loss coefficients obtained for each mixture at $\mathrm{V}>1 \mathrm{~m} / \mathrm{s}$

\begin{tabular}{|c|c|c|c|}
\hline Materials & $\begin{array}{l}\text { Density } \\
\left(\mathrm{kg} / \mathrm{m}^{3}\right)\end{array}$ & $\begin{array}{c}\mathbf{K}_{\text {valve Average }} \\
\quad(\mathrm{V}>\mathbf{1} \mathrm{m} / \mathrm{s})\end{array}$ & $\begin{array}{l}\text { Standard } \\
\text { Deviation }\end{array}$ \\
\hline Kaolin $10 \%$ & 1,164 & 0.60 & 0.20 \\
\hline Kaolin $10 \%+2 \%$ sand $0.7 \mathrm{~mm}$ & 1,172 & 0.57 & 0.21 \\
\hline Kaolin $10 \%+5 \%$ sand $0.7 \mathrm{~mm}$ & 1,249 & 0.48 & 0.19 \\
\hline Kaolin $10 \%+10 \%$ sand $0.7 \mathrm{~mm}$ & 1,271 & 0.55 & 0.14 \\
\hline Kaolin 20\% & 1,325 & 0.61 & 0.12 \\
\hline Kaolin $20 \%+2 \%$ sand $_{3 \mathrm{~mm}}$ & 1,401 & 0.40 & 0.14 \\
\hline Kaolin $20 \%+5 \%$ sand $3 \mathrm{~mm}$ & 1,534 & 0.40 & 0.21 \\
\hline Kaolin $20 \%+10 \%$ sand $3 \mathrm{~mm}$ & 1,586 & 0.46 & 0.25 \\
\hline
\end{tabular}

From Figure 8 it can be seen that the reduction in the loss coefficient is not affected by the concentration of sand added. The reduction is more pronounced for the higher concentration of kaolin. This is consistent with the behaviour in straight pipes observed by Charles and Charles (1971) and Ghosh and Shook (1990) where an introduction of particles in clay and polymeric shear-thinning fluids reduced the head losses. This present work was done to initiate investigation of these phenomena and present the first results for design engineers to consider. This is the first work done on this topic, and much further work is required. However, it is clear that for the materials tested and for velocities greater than $1 \mathrm{~m} / \mathrm{s}$, the existing turbulent flow loss coefficient data for Newtonian and homogeneous non-Newtonian fluids will result in conservative design estimates. However, for energy efficient designs, accurate loss coefficient data is required, and this research is ongoing. 


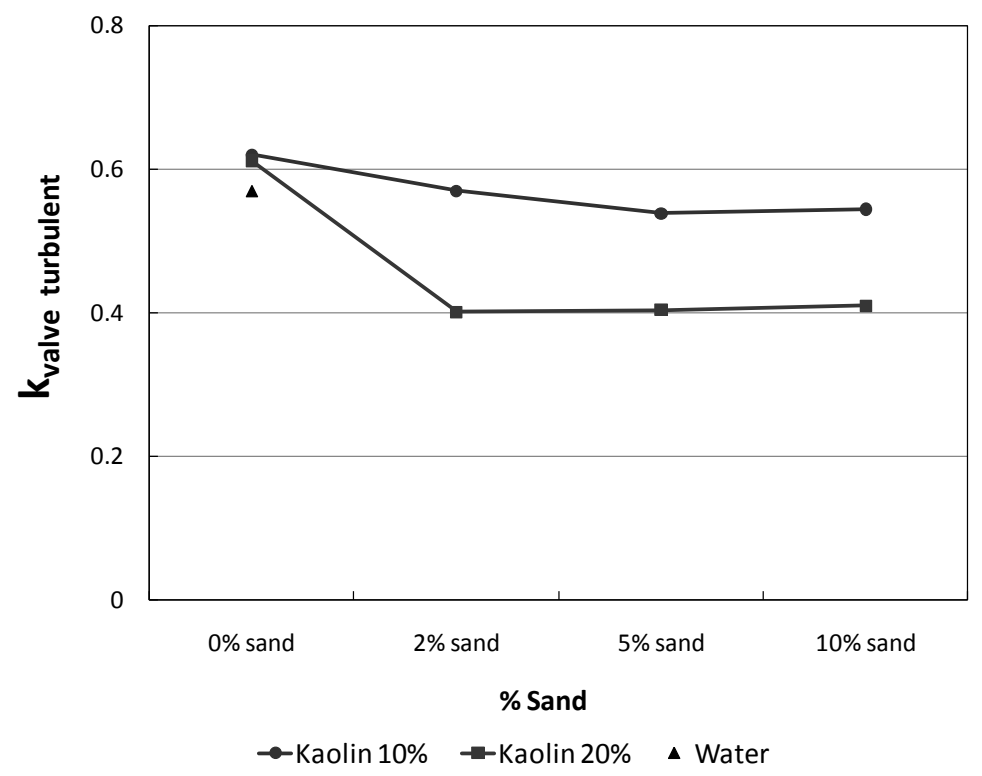

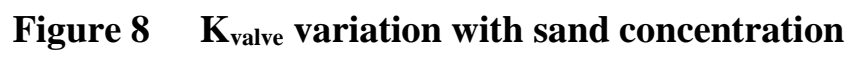

\section{Conclusions}

A $65 \mathrm{~mm}$ straight-through diaphragm valve has been mounted horizontally and tested at fully open position. Two concentrations of kaolin slurry carrier fluid, with three concentrations of coarse silica sand each, were tested over the pipe velocity range $0.1-3 \mathrm{~m} / \mathrm{s}$. Head loss coefficient data in the valve were determined using the pressure grade line method and presented as a function of pipe velocity.

It was found that the head loss coefficient increased with decreasing velocity at $\mathrm{V}<1 \mathrm{~m} / \mathrm{s}$. The order of magnitude is significant as $k_{\text {valve }}$ could rise from 0.7 at $\mathrm{V}=1 \mathrm{~m} / \mathrm{s}$ to 100 at $\mathrm{V}=0.1 \mathrm{~m} / \mathrm{s}$. This dependence diminishes at $\mathrm{V}>1 \mathrm{~m} / \mathrm{s}$ where the head loss coefficient becomes independent of the velocity.

The addition of coarse sand particles reduced the head loss coefficient. This reduction was independent of the concentration of sand added. It was also observed that the reduction of the head loss coefficient was increased as the concentration of the carrier fluid was increased. The effect of carrier concentration must be validated by using the same sand size in all concentrations of carrier fluid.

Although this work shows that the use of existing turbulent flow head loss coefficients for Newtonian and homogeneous non-Newtonian fluids will result in conservative designs, efficient design is only possible if accurate loss coefficient data are available.

This is the first time that these phenomena have been investigated, and important information on the loss coefficients in a diaphragm valve conveying coarse particles transported in a non-Newtonian carrier fluid has been provided. Further work in this area is continuing.

\section{References}

Charles, M.E. and Charles, R.A. (1971) Advances in solid-liquid flow and its applications, I. Zanid (ed), New York: Pergamon Press.

Cooke, R. (2002) Laminar flow settling: the potential for unexpected problems, in Proceedings 15th International Conference Hydraulic Transport of Solids: Hydrotransport 15, Banff, AB, Canada, BHR Group, Cranfield, UK, pp. 121-133.

Coussot, P. and Piau, J.M. (1995) The effects of an addition of force free particles on the rheological properties of fine suspensions, Canadian Geotechnical Journal, Vol. 32, pp. 263-270.

Crane Co. (1999) Flow of fluids through valves, fittings and pipes: metric edition - SI units, Technical paper no. 410M, London: Crane Co.

Duckworth, R.A., Pullum, L., Addie, G.R. and Lockyear, C.F. (1986) Pipeline transport of coarse materials in a nonNewtonian carrier fluid, Hydrotransport 10, Paper C2, pp. 69-68. 
Edwards, M.F., Jadallah, M.S.M. and Smith, R. (1985) Head losses in pipe fittings at low Reynolds numbers, Chemical Engineering Research and Design, January, Vol. 63, pp. 43-50.

Ghosh, T. and Shook, A. (1990) Freight pipelines, H. Liu and G.F. Round (eds), Washington DC: Hemisphere.

Hooper, W.B. (1981) The two-K method predicts head loss in pipe fittings, Chemical Engineering, Vol. 96-100, August.

Kabwe, A.M., Fester, V.G. and Slatter, P.T. (2010) Prediction of non-Newtonian head losses through diaphragm valves at different opening positions, Chemical Engineering Research and Design, Vol. 88, pp. 959-970.

Massey, B.S. (1970) Mechanics of fluids, 2nd edition, London, van Nostrand Reinhold.

Miller, D.S. (1990) Internal flow systems, 2nd edition, BHRA (Information Services), The Fluid Engineering Centre, Cranfield, UK.

Paulsen, E., Sumner, R.J. and Sanders, R.S. (2010) The effect of coarse particle addition on the rheology of fine clay slurries, British Hydromechanics Research Group 18th International Conference on Slurry Handling and Pipeline Transport, Hydrotransport 18, Rio de Janeiro, September 22-24.

Perry, R.H., Green, D.W. and Maloney, J.O. (1997) Perry's Chemical Engineering Handbook, 7th edition, New York: McGraw-Hill.

Pullum, L., Graham, L., Rudman, M. and Hamilton, R. (2006) High concentration suspension pumping, Minerals Engineering, Vol. 19, Issue 5, April, pp. 471-477.

Pullum, L., Slatter, P.T., Graham, L. and Chryss, A. (2010) Are tube viscometer data valid for suspension flows? Korea-Australia Rheology Journal, Vol. 22, No. 3, September, pp. 163-168.

Slatter, P.T. and Fester, V.G. (2010) Fittings losses in Paste Flow Design, in Proceedings 13th International Seminar on Paste and Thickened Tailings (Paste2010), R.J. Jewell and A.B. Fourie (eds), 3-6 May 2010, Toronto, Canada, Australian Centre for Geomechanics, Perth, pp. 303-310.

Streeter, V.L. and Wylie, B. (1985) Fluid Mechanics, 6th edition, McGraw-Hill Inc., USA.

Turian, R.M., Hsu F.L. and Sami Selim, M. (1983) Friction losses for flow of slurries in pipeline bends, fittings, and valves, Hemisphere Publishing Corporation, Particulate Science and Technology, Vol. 1, pp. 365-392. 